Jurnal Ilmiah Matematika dan Pendidikan Matematika (JMP)

Vol. 12 No. 1, Juni 2020, hal. 1-13

ISSN (Cetak) : 2085-1456; ISSN (Online) : 2550-0422

\title{
PEMECAHAN MASALAH KINEMATIKA KE DEPAN PADA TANGAN ROBOT $\boldsymbol{n}$-SEGMEN
}

\author{
Bambang Hendriya Guswanto \\ Jurusan Matematika, FMIPA Universitas Jenderal Soedirman \\ bambang.guswanto@unsoed.ac.id \\ Alisya Masturoh \\ Jurusan Matematika, FMIPA Universitas Jenderal Soedirman \\ Triyani \\ Jurusan Matematika, FMIPA Universitas Jenderal Soedirman
}

\begin{abstract}
This article discusses a forward kinematics space for a robot's hand with $n$ arms in two dimensional Euclid space. The kinematics space of the robot's hand is obtained by employing some geometrical transformations, those are rotation and dilatation. The solution of this problem is represented by a function corresponding a set of pairs of hinge configuration with a set of pairs of robot's position and hand endpoint direction.
\end{abstract}

Keywords: Geometry Transformations, Robot's Hand n-arms, Forward Kinematic Problem.

\begin{abstract}
ABSTRAK. Artikel ini membahas tentang ruang gerak kinematik ke depan tangan robot dengan $n$ lengan pada ruang Euclid berdimensi dua. Ruang kinematika tangan robot ini diperoleh dengan menggunakan beberapa tranformasi geometri yaitu rotasi dan dilatasi. Penyelesaian masalah kinematika ini direpresentasikan oleh suatu fungsi yang mengaitkan antara himpunan pasangan pengaturan sendi dan himpunan pasangan posisi dan arah ujung tangan robot.
\end{abstract}

Kata Kunci : Transformasi Geometri, Tangan Robot $n$-lengan, Permasalahan Gerak Kinematik ke Depan.

\section{PENDAHULUAN}

Artikel ini membahas tentang ruang gerak kinematik tangan robot dengan $n$ lengan. Tangan robot ini terdiri dari satu ujung tangan dan lengan-lengan atau disebut segmen, yang terhubung satu sama lain oleh suatu sendi. Jenis sendi yang ada pada tangan robot yang menjadi perhatian dalam artikel ini terdiri dari dua macam sendi yaitu sendi planar putar dan sendi prismatik. Jenis sendi planar putar memungkinkan pergerakan segmen secara memutar, sementara jenis sendi 
A. Masturoh et al.

prismatik memungkinkan gerakan pemanjangan dan pemendekan segmen. Bentuk pergerakan ini dapat direpresentasikan secara geometri melalui koordinat kartesius dengan titik pusat berada di sendinya. Gerak pada tangan robot ini dapat dipandang sebagai gerak kinematik. Salah satu permasalahan dalam gerak kinematik adalah permasalahan gerak kinematik ke depan, yaitu untuk menentukan posisi dan arah ujung tangan robot agar sesuai dengan pengaturanpengaturan sendi yang ada.

Penelitian mengenai permasalahan kinematika pada tangan robot pernah dilakukan oleh Natarajan, dkk [2]. Penelitian tersebut menganalisis kinematika tangan robot dengan tiga jari dengan menggunakan metode grafik. Adapun dalam artikel ini, pendekatan sistematis dengan menggunakan transformasi geometri khususnya rotasi dan dilatasi akan dilakukan untuk mendeskripsikan ruang gerak yang mungkin untuk tangan robot dengan $n$-segmen tersebut. Pendekatan ini nantinya akan digunakan untuk memecahkan pemasalahan gerak kinematik ke depan sebagai salah satu aplikasi dalam kajian Geometri Aljabar (lihat [1]).

\section{HASIL DAN PEMBAHASAN}

Langkah-langkah yang dilakukan untuk menyelesaikan permasalahan kinematika tangan robot dengan $n$-segmen ini :

1. mendeskripsikan bentuk dan cara kerja sendi pada lengan robot sebagai berikut:

a. sendi planar putar memungkinkan gerakan memutar antara dua segmen yang berhubungan;

b. sendi prismatik memungkinkan gerakan perpanjangan dan pemendekan suatu segmen;

c. satu tangan robot terdiri dari beberapa segmen, dengan setiap dua segmen yang berurutan terhubung dengan satu jenis sendi;

d. posisi dan arah segmen pertama tetap, sementara posisi dan arah segmen lain dapat berubah dengan rotasi dan translasi.

2. merepresentasikan tangan robot dalam bentuk geometri pada sistem koordinat kartesius $\mathbb{R}^{2}$ dengan ketentuan sebagai berikut: 
a. pusat koordinat berada di setiap sendi planar putar pada lengan robot;

b. $\left(x_{1}, y_{1}\right)$ merupakan sistem koordinat global;

c. untuk $i>1,\left(x_{i}, y_{i}\right)$ merupakan sistem koordinat lokal dengan pusat di sendi ke- $(i-1)$ dan sumbu- $x_{i}$ searah dengan arah lengan ke- $i$.

3. mendeskripsikan gerak sendi melalui rotasi dan translasi (pembahasan lengkap tentang transformasi geometri ini bisa melihat Wallace dan West [2] atau Schwatrz [3]);

4. mendefinisikan gerak sendi dengan suatu pemetaan polinomial $f: J \rightarrow C$ dengan kriteria sebagai berikut:

a. himpunanJmerupakan himpunan pengaturan sendi-sendi yang memungkinkan atau ruang sendi dan $C$ merupakan himpunan posisi dan arah koordinat yang memungkinkan atau ruang konfigurasi;

b. himpunan $J$ didapatkan dari hasil perkalian kartesian semua kemungkinan pengaturan sendi-sendi planar putar dan semua pengaturan sendi-sendi prismatik;

c. pada suatu sendi planar putar, pengaturan sendi antara segmen ke- $i$ dengan segmen ke- $(i+1)$ dideskripsikan dengan mengitung besar sudut yang terbentuk antara kedua segmen tersebut secara berlawanan arah jarum jam;

d. keseluruhan kemungkinan pengaturan suatu sendi planar putar diparameterkan oleh lingkaran satuan atau interval $[0,2 \pi]$;

e. pada sendi prismatik, pengaturan sendi dideskripsikan dengan menghitung panjang segmen yang dihasilkan oleh sendi yang bersangkutan;

f. keseluruhan pengaturan suatu sendi prismatik yang memungkinkan diparameterkan oleh suatu interval bilangan asli $\left[m_{1}, m_{2}\right]$, dengan $m_{1}$ merupakan panjang minimum segmen dan $m_{2}$ merupakan panjang maksimum segmen;

g. himpunan $C$ didapatkan dari hasil perkalian kartesian dari himpunan posisi ujung tangan dan himpunan arah ujung tangan. 
h. posisi ujung tangan diparameterkan oleh pasangan terurut $(a, b)$ yang merupakan suatu titik pada sistem koordinat $\left(x_{1}, y_{1}\right)$;

i. arah ujung tangan diparamaterkan oleh suatu vektor satuan yang sejajar dengan bentuk spesifik ujung tangan;

Setiap tangan robot memiliki segmen pertama yang posisinya tetap. Dalam hal ini, sistem koordinat global $\left(x_{1}, y_{1}\right)$ yang merupakan sistem koordinat utama tangan robot memiliki titik pusat yang berada pada sendi planar putar pertama. Selain sistem koordinat global, terdapat juga sistem koordinat lokal $\left(x_{i}, y_{i}\right)$ yang memiliki titik pusat pada sendi planar putar ke-(i-1) dengan sumbu- $x_{i}$ searah dengan lengan segmen ke- $i$.

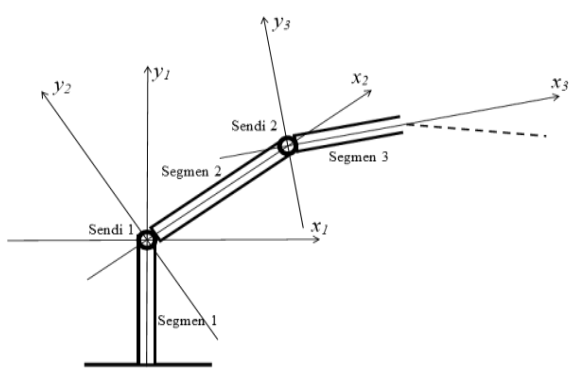

Gambar 2.1 Sistem koordinat pada tangan robot

\subsection{Hubungan antar koordinat}

Misalkan terdapat dua segmen yang bersangkutan yaitu segmen ke- $i$ dan segmen ke- $(i+1)$. Penggambaran sistem koordinat $\left(x_{i}, y_{i}\right)$ dan sistem koordinat $\left(x_{i+1}, y_{i+1}\right)$ digambarkan dalam Gambar 2.1.

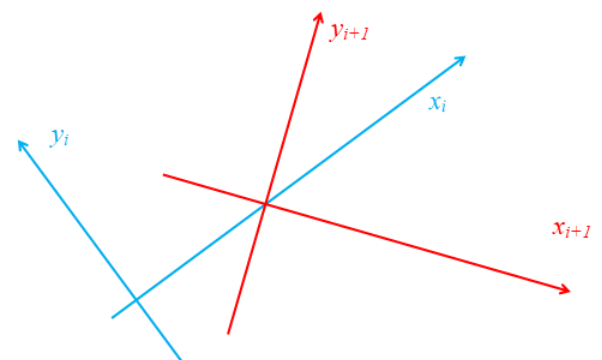

Gambar 2.2 Sistem koordinat $\left(x_{i}, y_{i}\right)$ dan sistem koordinat $\left(x_{i+1}, y_{i+1}\right)$ 
Sistem koordinat $\left(x_{i}, y_{i}\right)$ dan sistem koordinat $\left(x_{i+1}, y_{i+1}\right)$ dihubungkan oleh pengaturan sendi planar putar ke- $i$ dan juga sendi prismatik pada segmen ke- $i$ (jika ada). Misalkan arah pengaturan sendi planar putar ke- $i$ sebesar $\theta_{i}$ dan panjang sendi prismatik ke- $i$ sebesar $l_{i}$.

Misalkan juga posisi ujung tangan dalam sistem koordinat $\left(x_{i+1}, y_{i+1}\right)$ adalah $\left(a_{i+1}, b_{i+1}\right)$. Posisi ujung tangan dalam sistem koordinat $\left(x_{i}, y_{i}\right)$ yaitu $\left(a_{i}, b_{i}\right)$ akan ditentukan. Untuk mencarinya, transformasikan sistem koordinat $\left(x_{i}, y_{i}\right)$ agar memiliki posisi yang sama persis dengan sistem koordinat $\left(x_{i+1}, y_{i+1}\right)$.

Pertama, rotasikan sistem koordinat $\left(x_{i}, y_{i}\right)$ sebesar $\theta_{i}$ terhadap sumbu rotasi $(0,0)$ pada sistem koordinat $\left(x_{i+1}, y_{i+1}\right)$. Kedua, translasikan sistem koordinat $\left(x_{i}, y_{i}\right)$ terhadap vektor $\left\langle l_{i}, 0\right\rangle$ agar memiliki titik pusat yang sama.

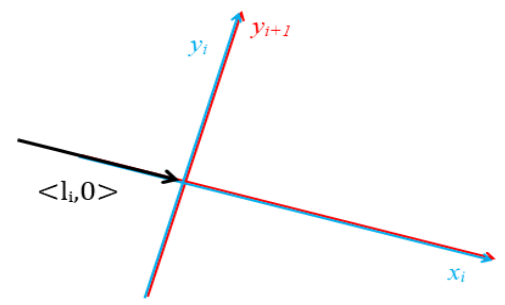

Gambar 2.3 Hasil translasi dan rotasi sistem koordinat $\left(x_{i}, y_{i}\right)$

\subsection{Transformasi sistem koordinat}

Misalkan $\left(a_{i}, b_{i}\right)$ merupakan titik pada sistem koordinat $\left(x_{i}, y_{i}\right)$. Rotasi sebesar $\theta_{i}$ dirumuskan dalam persamaan matriks

$$
\left(\begin{array}{l}
a_{i}^{\prime} \\
b_{i}^{\prime}
\end{array}\right)=\left(\begin{array}{cc}
\cos \theta_{i} & -\sin \theta_{i} \\
\sin \theta_{i} & \cos \theta_{i}
\end{array}\right)\left(\begin{array}{l}
a_{i+1} \\
b_{i+1}
\end{array}\right)=\left(\begin{array}{c}
a_{i+1} \cos \theta_{i}-b_{i+1} \sin \theta_{i} \\
a_{i+1} \sin \theta_{i}+b_{i+1} \cos \theta_{i}
\end{array}\right) .
$$

Selanjutnya, translasi terhadap vektor $\left\langle l_{i}, 0\right\rangle$ dirumuskan dalam persamaan matriks

$$
\left(\begin{array}{l}
a_{i} \\
b_{i}
\end{array}\right)=\left(\begin{array}{l}
a_{i+1} \cos \theta_{i}-b_{i+1} \sin \theta_{i} \\
a_{i+1} \sin \theta_{i}+b_{i+1} \cos \theta_{i}
\end{array}\right)+\left(\begin{array}{l}
l_{i} \\
0
\end{array}\right)=\left(\begin{array}{l}
a_{i+1} \cos \theta_{i}-b_{i+1} \sin \theta_{i}+l_{i} \\
a_{i+1} \sin \theta_{i}+b_{i+1} \cos \theta_{i}
\end{array}\right) .
$$


Sehingga, sembarang titik $\left(a_{i+1}, b_{i+1}\right)$ dalam sistem koodinat $\left(x_{i}, y_{i}\right)$ akan memiliki nilai

$$
\left(a_{i}, b_{i}\right)=\left(a_{i+1} \cos \theta_{i}-b_{i+1} \sin \theta_{i}+l_{i}, a_{i+1} \sin \theta_{i}+b_{i+1} \cos \theta_{i}\right) .
$$

Hasil ini juga dapat dituliskan dalam bentuk matriks $3 \times 1$, yaitu

$$
\left(\begin{array}{c}
a_{i} \\
b_{i} \\
1
\end{array}\right)=\left(\begin{array}{c}
a_{i+1} \cos \theta_{i}-b_{i+1} \sin \theta_{i}+l_{i} \\
a_{i+1} \sin \theta_{i}+b_{i+1} \cos \theta_{i} \\
1
\end{array}\right)=\left(\begin{array}{ccc}
\cos \theta_{i} & -\sin \theta_{i} & l_{i} \\
\sin \theta_{i} & \cos \theta_{i} & 0 \\
0 & 0 & 1
\end{array}\right)\left(\begin{array}{c}
a_{i+1} \\
b_{i+1} \\
1
\end{array}\right) .
$$

Jadi, untuk mencari koordinat titik $\left(a_{i+1}, b_{i+1}\right)$ dalam sistem koordinat $\left(x_{i}, y_{i}\right)$, matriks $3 \times 3$ yang digunakan adalah

$$
\left(\begin{array}{ccc}
\cos \theta_{i} & -\sin \theta_{i} & l_{i} \\
\sin \theta_{i} & \cos \theta_{i} & 0 \\
0 & 0 & 1
\end{array}\right)
$$

Selanjutnya, matriks ini disebut matriks $A_{i}$, yaitu matriks yang menghubungkan sistem koordinat $\left(x_{i}, y_{i}\right)$ dengan sistem koordinat $\left(x_{i+1}, y_{i+1}\right)$.

Perhatikan bahwa pengaturan antara sistem koordinat global $\left(x_{1}, y_{1}\right)$ dengan dengan sistem koordinat $\left(x_{2}, y_{2}\right)$ dipisahkan dengan rotasi saja. Dengan kata lain, translasinya adalah $(0,0)$. Jadi,

$$
A_{1}=\left(\begin{array}{ccc}
\cos \theta_{1} & -\sin \theta_{1} & 0 \\
\sin \theta_{1} & \cos \theta_{1} & 0 \\
0 & 0 & 1
\end{array}\right)
$$

\subsection{Tangan robot $n$-segmen}

Misalkan terdapat suatu tangan robot bersegmen $n$ dengan $r$ sendi planar putar dan $p$ sendi prismatik. Apabila ujung tangan menempel pada suatu lengan sepanjang $l_{n}$ tanpa ada sekat sendi planat putar, maka dianggap sebagai satu kesatuan segmen dengan satu ujung tangan dan satu lengan dengan panjang $l_{n}$. 
Apabila terdapat sendi planar putar, maka ujung tangan ini tetap dianggaap satu segmen dengan satu ujung tangan dan satu lengan dengan panjang 0.

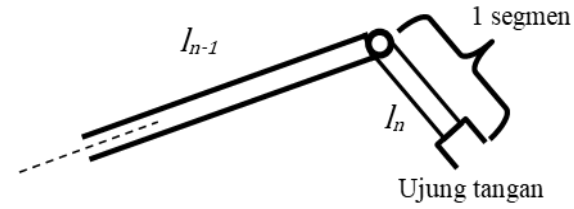

(a) Ujung lengan menempel pada lengan ke- $n$

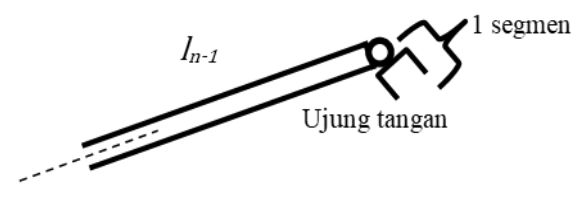

(b) Ujung lengan menempel pada sendi ke- $n$

Gambar 2.4 Ilustrasi ujung lengan

Apabila pada $l_{i}$ terdapat sendi prismatik, maka nilai $l_{i}$ bergantung pada pengaturan sendi prismatiknya. Sebaliknya, apabila pada $l_{i}$ tidak terdapat sendi prismatik, maka nilai $l_{i}$ tetap dan dapat diketahui sejak awal. Jika pada $l_{i}$ terdapat lebih dari satu sendi prismatik yang berturut-turut tanpa disekat oleh sendi planar putar, maka $l_{i}$ dianggap sebagai satu kesatuan lengan atau segmen. Karena itu, untuk tangan dengan $n$ segmen akan memiliki $n-1$ sendi planar putar. Hal ini menyebabkan banyaknya sistem koordinat pada suatu tangan robot bersegmen- $n$ adalah $n$.

Misalkan $\left(a_{i}, b_{i}\right)$ merupakan sebuah titik pada sistem koordinat $\left(x_{i}, y_{i}\right)$. Transformasi dari sistem koordinat $\left(x_{2}, y_{2}\right)$ ke sistem koordinat $\left(x_{1}, y_{1}\right)$ memerlukan matriks $A_{1}$ yang secara matematis dirumuskan sebagai

$$
\left(\begin{array}{c}
a_{1} \\
b_{1} \\
1
\end{array}\right)=A_{1}\left(\begin{array}{c}
a_{2} \\
b_{2} \\
1
\end{array}\right)
$$

Titik $\left(a_{2}, b_{2}\right)$ didapatkan melalui transformasi dari sistem koordinat $\left(x_{3}, y_{3}\right)$ ke sistem koordinat $\left(x_{2}, y_{2}\right)$, sehingga

$$
\left(\begin{array}{c}
a_{1} \\
b_{1} \\
1
\end{array}\right)=A_{1} A_{2}\left(\begin{array}{c}
a_{3} \\
b_{3} \\
1
\end{array}\right) .
$$


A. Masturoh et al.

Dengan cara yang sama, $\left(a_{3}, b_{3}\right)$ didapatkan melalui transformasi dari sistem koordinat $\left(x_{4}, y_{4}\right)$ ke sistem koordinat $\left(x_{3}, y_{3}\right)$. Jika proses ini terus dilanjutkan maka

$$
\left(\begin{array}{c}
a_{1} \\
b_{1} \\
1
\end{array}\right)=A_{1} A_{2} \cdots A_{n-1}\left(\begin{array}{c}
a_{n} \\
b_{n} \\
1
\end{array}\right),
$$

dengan

$$
A_{i}=\left(\begin{array}{ccc}
\cos \theta_{i} & -\sin \theta_{i} & l_{i} \\
\sin \theta_{i} & \cos \theta_{i} & 0 \\
0 & 0 & 1
\end{array}\right)
$$

Selanjutnya, perhatikan bahwa

$$
\begin{aligned}
& A_{i} A_{i+1}=\left(\begin{array}{ccc}
\cos \theta_{i} & -\sin \theta_{i} & l_{i} \\
\sin \theta_{i} & \cos \theta_{i} & 0 \\
0 & 0 & 1
\end{array}\right)\left(\begin{array}{ccc}
\cos \theta_{i+1} & -\sin \theta_{i+1} & l_{i+1} \\
\sin \theta_{i+1} & \cos \theta_{i+1} & 0 \\
0 & 0 & 1
\end{array}\right)=\left(\begin{array}{ccc}
\cos \left(\theta_{i}+\theta_{i+1}\right) & -\sin \left(\theta_{i}+\theta_{i+1}\right) & l_{i+1} \cos \theta_{i}+l_{i} \\
\sin \left(\theta_{i}+\theta_{i+1}\right) & \cos \left(\theta_{i}+\theta_{i+1}\right) & l_{i+1} \sin \theta_{i} \\
0 & 0 & 1
\end{array}\right), \\
& A_{i} A_{i+1} A_{i+2}=\left(A_{i} A_{i+1}\right) A_{i+2}=\left(\begin{array}{ccc}
\cos \left(\theta_{i}+\theta_{i+1}+\theta_{i+2}\right) & -\sin \left(\theta_{i}+\theta_{i+1}+\theta_{i+2}\right) & l_{i+2} \cos \left(\theta_{i}+\theta_{i+1}\right)+l_{i+1} \cos \theta_{i}+l_{i} \\
\sin \left(\theta_{i}+\theta_{i+1}+\theta_{i+2}\right) & \cos \left(\theta_{i}+\theta_{i+1}+\theta_{i+2}\right) & l_{i+2} \sin \left(\theta_{i}+\theta_{i+1}\right)+l_{i+1} \sin \theta_{i} \\
0 & 0 & 1
\end{array}\right) \text {, } \\
& A_{i} A_{i+1} A_{i+2} A_{i+3}=\left(\begin{array}{ccc}
\cos \left(\theta_{i}+\cdots+\theta_{i+3}\right) & -\sin \left(\theta_{i}+\cdots+\theta_{i+3}\right) & l_{i+3} \cos \left(\theta_{i}+\theta_{i+1}+\theta_{i+2}\right)+l_{i+2} \cos \left(\theta_{i}+\theta_{i+1}\right)+l_{i+1} \cos \theta_{i}+l_{i} \\
\sin \left(\theta_{i}+\cdots+\theta_{i+3}\right) & \cos \left(\theta_{i}+\cdots+\theta_{i+3}\right) & l_{i+3} \sin \left(\theta_{i}+\theta_{i+1}+\theta_{i+2}\right)+l_{i+2} \sin \left(\theta_{i}+\theta_{i+1}\right)+l_{i+1} \sin \theta_{i} \\
0 & 0 & 1
\end{array}\right),
\end{aligned}
$$

dan seterusnya. Jadi,

$$
A_{2} A_{3} \cdots A_{n-1}=\left(\begin{array}{ccc}
\cos \left(\theta_{2}+\cdots+\theta_{n-1}\right) & -\sin \left(\theta_{2}+\cdots+\theta_{n-1}\right) & l_{i}+\sum_{i=2}^{n-2} l_{i+1} \cos \left(\theta_{2}+\cdots+\theta_{i}\right) \\
\sin \left(\theta_{2}+\cdots+\theta_{n-1}\right) & \cos \left(\theta_{2}+\cdots+\theta_{n-1}\right) & \sum_{i=2}^{n-2} l_{i+1} \sin \left(\theta_{2}+\cdots+\theta_{i}\right) \\
0 & 0 & 1
\end{array}\right) .
$$

Akibatnya,

$$
A_{1} A_{2} A_{3} \cdots A_{n-1}=A_{1}\left(A_{2} A_{3} \cdots A_{n-1}\right)=\left(\begin{array}{ccc}
\cos \left(\theta_{1}+\cdots+\theta_{n-1}\right) & -\sin \left(\theta_{1}+\cdots+\theta_{n-1}\right) & \sum_{i=1}^{n-2} l_{i+1} \cos \left(\theta_{1}+\cdots+\theta_{i}\right) \\
\sin \left(\theta_{1}+\cdots+\theta_{n-1}\right) & \cos \left(\theta_{1}+\cdots+\theta_{n-1}\right) & \sum_{i=1}^{n-2} l_{i+1} \sin \left(\theta_{1}+\cdots+\theta_{i}\right) \\
0 & 0 & 1
\end{array}\right)
$$


Selanjutnya, misalkan $A^{(\mathrm{n})}=A_{1} A_{2} A_{3} \cdots A_{n-1}$. Akan dibuktikan bahwa matriks $A^{(\mathrm{n})}$ yang menunjukan matriks transformasi dari sistem koordinat $\left(x_{n}, y_{n}\right)$ ke sistem koordinat $\left(x_{1}, y_{1}\right)$ untuk tangan robot bersegmen- $n$ dengan sembarang bilangan asli $n \geq 2$ adalah

$$
A^{(\mathrm{n})}=\left(\begin{array}{ccc}
\cos \left(\theta_{1}+\cdots+\theta_{n-1}\right) & -\sin \left(\theta_{1}+\cdots+\theta_{n-1}\right) & \sum_{i=1}^{n-2} l_{i+1} \cos \left(\theta_{1}+\cdots+\theta_{i}\right) \\
\sin \left(\theta_{1}+\cdots+\theta_{n-1}\right) & \cos \left(\theta_{1}+\cdots+\theta_{n-1}\right) & \sum_{i=1}^{n-2} l_{i+1} \sin \left(\theta_{1}+\cdots+\theta_{i}\right) \\
0 & 0 & 1
\end{array}\right) .
$$

Diketahui bahwa

$$
A_{1}=\left(\begin{array}{ccc}
\cos \left(\theta_{1}\right) & -\sin \left(\theta_{1}\right) & 0 \\
\sin \left(\theta_{1}\right) & \cos \left(\theta_{1}\right) & 0 \\
0 & 0 & 1
\end{array}\right) \text { dan } A_{i}=\left(\begin{array}{ccc}
\cos \left(\theta_{i}\right) & -\sin \left(\theta_{i}\right) & l_{i} \\
\sin \left(\theta_{i}\right) & \cos \left(\theta_{i}\right) & 0 \\
0 & 0 & 1
\end{array}\right)
$$

Pertama, untuk $n=3$,

$$
\begin{aligned}
A^{(3)} & =A_{1} A_{2}=\left(\begin{array}{ccc}
\cos \left(\theta_{1}+\theta_{2}\right) & -\sin \left(\theta_{1}+\theta_{2}\right) & l_{2} \cos \theta_{1} \\
\sin \left(\theta_{1}+\theta_{2}\right) & \cos \left(\theta_{1}+\theta_{2}\right) & l_{2} \sin \theta_{1} \\
0 & 0 & 1
\end{array}\right) \\
& =\left(\begin{array}{ccc}
\cos \left(\theta_{1}+\cdots+\theta_{3-1}\right) & -\sin \left(\theta_{1}+\cdots+\theta_{3-1}\right) & \sum_{i=1}^{3-2} l_{i+1} \cos \left(\theta_{1}+\cdots+\theta_{i}\right) \\
\sin \left(\theta_{1}+\cdots+\theta_{3-1}\right) & \cos \left(\theta_{1}+\cdots+\theta_{3-1}\right) & \sum_{i=1}^{3-2} l_{i+1} \sin \left(\theta_{1}+\cdots+\theta_{i}\right) \\
0 & 0 & 1
\end{array}\right)
\end{aligned}
$$

Andaikan, untuk $n=s$,

$$
A^{(s)}=A_{1} A_{2} A_{3} \cdots A_{s-1}=\left(\begin{array}{ccc}
\cos \left(\theta_{1}+\cdots+\theta_{s-1}\right) & -\sin \left(\theta_{1}+\cdots+\theta_{s-1}\right) & \sum_{i=1}^{s-2} l_{i+1} \cos \left(\theta_{1}+\cdots+\theta_{i}\right) \\
\sin \left(\theta_{1}+\cdots+\theta_{s-1}\right) & \cos \left(\theta_{1}+\cdots+\theta_{s-1}\right) & \sum_{i=1}^{s-2} l_{i+1} \sin \left(\theta_{1}+\cdots+\theta_{i}\right) \\
0 & 0 & 1
\end{array}\right) .
$$

Akan dibuktikan bahwa, untuk $n=s+1$, 


$$
A^{(s+1)}=A_{1} A_{2} A_{3} \cdots A_{s}=\left(\begin{array}{ccc}
\cos \left(\theta_{1}+\cdots+\theta_{s}\right) & -\sin \left(\theta_{1}+\cdots+\theta_{s}\right) & \sum_{i=1}^{s-1} l_{i+1} \cos \left(\theta_{1}+\cdots+\theta_{i}\right) \\
\sin \left(\theta_{1}+\cdots+\theta_{s}\right) & \cos \left(\theta_{1}+\cdots+\theta_{s}\right) & \sum_{i=1}^{s-1} l_{i+1} \sin \left(\theta_{1}+\cdots+\theta_{i}\right) \\
0 & 0 & 1
\end{array}\right)
$$

Perhatikan bahwa

$$
\begin{aligned}
& A^{(s)}=A_{1} A_{2} A_{3} \cdots A_{s}=\left(A_{1} A_{2} A_{3} \cdots A_{s-1}\right) A_{s} \\
& =\left(\begin{array}{ccc}
\cos \left(\theta_{1}+\cdots+\theta_{s-1}\right) & -\sin \left(\theta_{1}+\cdots+\theta_{s-1}\right) & \sum_{i=1}^{s-2} l_{i+1} \cos \left(\theta_{1}+\cdots+\theta_{i}\right) \\
\sin \left(\theta_{1}+\cdots+\theta_{s-1}\right) & \cos \left(\theta_{1}+\cdots+\theta_{s-1}\right) & \sum_{i=1}^{s-2} l_{i+1} \sin \left(\theta_{1}+\cdots+\theta_{i}\right) \\
0 & 0 & 1
\end{array}\right)\left(\begin{array}{ccc}
\cos \theta_{s} & -\sin \theta_{s} & l_{s} \\
\sin \theta_{s} & \cos \theta_{s} & 0 \\
0 & 0 & 1
\end{array}\right) \\
& =\left(\begin{array}{ccc}
\cos \left(\theta_{1}+\cdots+\theta_{s}\right) & -\sin \left(\theta_{1}+\cdots+\theta_{s}\right) & \sum_{i=1}^{s-1} l_{i+1} \cos \left(\theta_{1}+\cdots+\theta_{i}\right) \\
\sin \left(\theta_{1}+\cdots+\theta_{s}\right) & \cos \left(\theta_{1}+\cdots+\theta_{s}\right) & \sum_{i=1}^{s-1} l_{i+1} \sin \left(\theta_{1}+\cdots+\theta_{i}\right) \\
0 & 0 & 1
\end{array}\right) .
\end{aligned}
$$

Jadi, terbukti bahwa matriks $A^{(n-1)}$ untuk sembarang tangan robot bersegmen- $n$ adalah

$$
A^{(n-1)}=\left(\begin{array}{ccc}
\cos \left(\theta_{1}+\cdots+\theta_{n-1}\right) & -\sin \left(\theta_{1}+\cdots+\theta_{n-1}\right) & \sum_{i=1}^{n-2} l_{i+1} \cos \left(\theta_{1}+\cdots+\theta_{i}\right) \\
\sin \left(\theta_{1}+\cdots+\theta_{n-1}\right) & \cos \left(\theta_{1}+\cdots+\theta_{n-1}\right) & \sum_{i=1}^{n-2} l_{i+1} \sin \left(\theta_{1}+\cdots+\theta_{i}\right) \\
0 & 0 & 1
\end{array}\right) .
$$

Didapatkan bahwa posisi ujung tangan robot dalam sistem koordinat global adalah

$$
\left(\begin{array}{c}
a_{1} \\
b_{1} \\
1
\end{array}\right)=\left(\begin{array}{ccc}
\cos \left(\theta_{1}+\cdots+\theta_{n-1}\right) & -\sin \left(\theta_{1}+\cdots+\theta_{n-1}\right) & \sum_{i=1}^{n-2} l_{i+1} \cos \left(\theta_{1}+\cdots+\theta_{i}\right) \\
\sin \left(\theta_{1}+\cdots+\theta_{n-1}\right) & \cos \left(\theta_{1}+\cdots+\theta_{n-1}\right) & \sum_{i=1}^{n-2} l_{i+1} \sin \left(\theta_{1}+\cdots+\theta_{i}\right) \\
0 & 0 & 1
\end{array}\right)\left(\begin{array}{c}
a_{n} \\
b_{n} \\
1
\end{array}\right),
$$

dengan titik $\left(a_{n}, b_{n}\right)$ merupakan posisi ujung tangan robot bersegmen- $n$ dalam sistem koordinat $\left(x_{n}, y_{n}\right)$. 


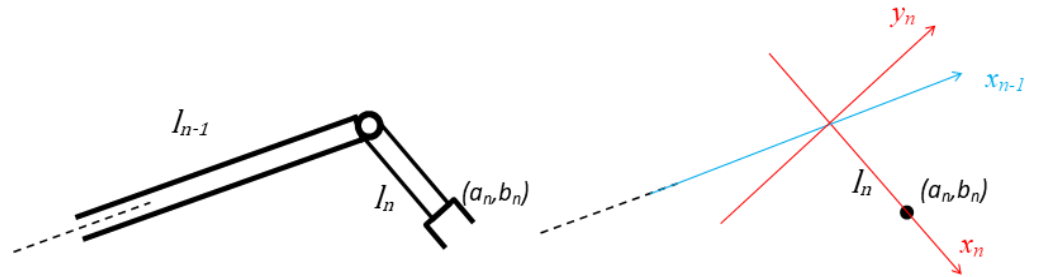

Gambar 2.5 Posisi ujung tangan dalam sistem koordinat $\left(x_{n}, y_{n}\right)$

Berdasarkan pengaturan sistem koordinat, posisi ujung tangan terhadap koordiat $\left(x_{n}, y_{n}\right)$ adalah $\left(l_{n}, 0\right)$ dengan $l_{n}$ adalah panjang lengan ke $-n$. Jadi, nilai $\left(a_{1}, b_{1}\right)$ adalah

$$
\left(\begin{array}{l}
a_{1} \\
b_{1} \\
1
\end{array}\right)=\left(\begin{array}{ccc}
\cos \left(\theta_{1}+\cdots+\theta_{n-1}\right) & -\sin \left(\theta_{1}+\cdots+\theta_{n-1}\right) & \sum_{i=1}^{n-2} l_{i+1} \cos \left(\theta_{1}+\cdots+\theta_{i}\right) \\
\sin \left(\theta_{1}+\cdots+\theta_{n-1}\right) & \cos \left(\theta_{1}+\cdots+\theta_{n-1}\right) & \sum_{i=1}^{n-2} l_{i+1} \sin \left(\theta_{1}+\cdots+\theta_{i}\right) \\
0 & 0 & 1
\end{array}\right)\left(\begin{array}{l}
l_{n} \\
0 \\
1
\end{array}\right)=\left(\begin{array}{c}
\sum_{i=1}^{n-1} l_{i+1} \cos \left(\theta_{1}+\cdots+\theta_{i}\right) \\
\sum_{i=1}^{n-1} l_{i+1} \sin \left(\theta_{1}+\cdots+\theta_{i}\right) \\
1
\end{array}\right) .
$$

Dengan kata lain,

$$
\left(\begin{array}{l}
a_{1} \\
b_{1} \\
1
\end{array}\right)=\left(\begin{array}{c}
\sum_{i=2}^{n} l_{i} \cos \left(\theta_{1}+\cdots+\theta_{i-1}\right) \\
\sum_{i=2}^{n} l_{i} \sin \left(\theta_{1}+\cdots+\theta_{i-1}\right) \\
1
\end{array}\right)
$$

Arah ujung tangan direpresentasikan dalam vektor satuan. Selain itu, arah ujung tangan dapat juga dituliskan dalam bentuk sudut. Misalkan $\theta$ merupakan arah ujung tangan dalam sistem koordinat global. Pada tangan robot dengan dua segmen, besar sudut $\theta$ sama dengan besar sudut $\theta_{1}$. Selanjutnya untuk tangan robot dengan tiga segmen, besar sudut $\theta$ sama dengan besar sudut $\theta_{1}+\theta_{2}$.

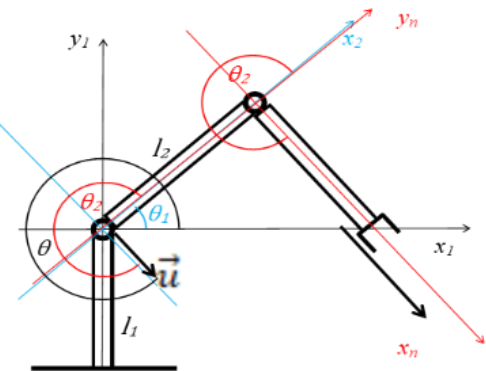

Gambar 2.6 Sudut tangan robot tiga segmen 
Oleh karena itu, untuk tangan robot dengan $n$ segmen, arah ujung tangan robot adalah

$$
\theta=\theta_{1}+\theta_{2}+\cdots+\theta_{n-1}
$$

Jadi, posisi dan arah ujung tangan robot dalam sistem koordinat global adalah

$$
\left(\begin{array}{l}
a_{1} \\
b_{1} \\
\theta
\end{array}\right)=\left(\begin{array}{c}
\sum_{i=2}^{n} l_{i} \cos \left(\theta_{1}+\cdots+\theta_{i-1}\right) \\
\sum_{i=2}^{n} l_{i} \sin \left(\theta_{1}+\cdots+\theta_{i-1}\right) \\
\sum_{i=1}^{n-1} \theta_{i}
\end{array}\right)
$$

Berdasarkan Persamaan (2.1), dapat disimpulkan bahwa posisi dan arah ujung tangan dalam sistem koordinat global bergantung pada nilai $\theta_{1}, \cdots, \theta_{n-1}, l_{2}, \cdots l_{n}$ atau dapat dinyatakan sebagai suatu fungsi $f: J \rightarrow C$ dengan

$$
f\left(\theta_{1}, \cdots, \theta_{n-1}, l_{2}, \cdots l_{n}\right)=\left(\begin{array}{c}
\sum_{i=2}^{n} l_{i} \cos \left(\theta_{1}+\cdots+\theta_{i-1}\right) \\
\sum_{i=2}^{n} l_{i} \sin \left(\theta_{1}+\cdots+\theta_{i-1}\right) \\
\sum_{i=1}^{n-1} \theta_{i}
\end{array}\right)
$$

dengan $J$ merupakan himpunan pasangan pengaturan sendi atau ruang sendi dan $C$ merupakan himpunan pasangan posisi dan arah ujung tangan atau ruang konfigurasi.

\section{KESIMPULAN DAN SARAN}

Posisi dan arah ujung tangan robot $n$-segmen dalam sistem koordinat global bergantung pada nilai $\theta_{1}, \cdots, \theta_{n-1}, l_{2}, \cdots l_{n}$ atau dapat dinyatakan sebagai suatu fungsi $f: J \rightarrow C$

$$
f\left(\theta_{1}, \cdots, \theta_{n-1}, l_{2}, \cdots l_{n}\right)=\left(\begin{array}{l}
a \\
b \\
\theta
\end{array}\right)=\left(\begin{array}{c}
\sum_{i=2}^{n} l_{i} \cos \left(\theta_{1}+\cdots+\theta_{i-1}\right) \\
\sum_{i=2}^{n} l_{i} \sin \left(\theta_{1}+\cdots+\theta_{i-1}\right) \\
\sum_{i=1}^{n-1} \theta_{i}
\end{array}\right),
$$

dengan $J$ merupakan himpunan pasangan pengaturan sendi atau ruang sendi dan $C$ merupakan himpunan pasangan posisi dan arah ujung tangan atau ruang konfigurasi. 


\section{DAFTAR PUSTAKA}

[1] Cox, D., Little, J., dan O'Shea, D., Ideals, Varieties, and Algorithms : An Introduction to Computational Algebraic Geometry and Comutative Algebra, Springer, New York, 2007.

[2] Natarajan, Elango, Dhar, L., Kinematic Analysis of Three Fingered Robot Hand Using Graphical Method, International Journal of Engineering and Technology, 5 (4) (2013), 518-522.

[3] Schwatrz, A., Analytic Geometry and Calculus, Hat, Rinehart, and Witson Inc, USA, 1960.

[4] Wallace, E.C. dan West, S.F., Road to Geometry, Waveland Press, Inc., USA, 2004. 